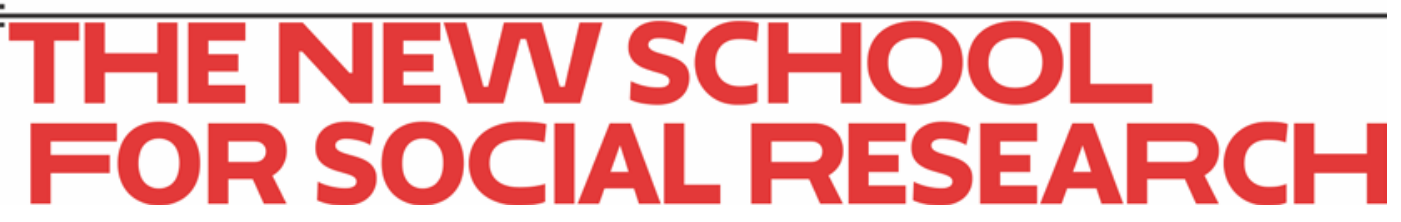

Eduardo F. Bastian and Mark Setterfield

\title{
A Simple Analytical Model of the Adverse Real Effects of Inflation
}

August 2015

Working Paper 19/2015

Department of Economics

The New School for Social Research 


\title{
A Simple Analytical Model of the Adverse Real Effects of Inflation
}

\author{
Eduardo F. Bastian \\ Institute of Economics, Federal University of Rio de Janeiro (IE-UFRJ) \\ eduardobastian@ie.ufrj.br \\ and \\ Mark Setterfield \\ New School for Social Research \\ and Trinity College, CT \\ mark.setterfield@newschool.edu
}

August 2015

\begin{abstract}
The essential insight advanced in this paper is that the claim that inflation can impair growth makes most sense in the context of a monetary production economy, wherein a role for money in the determination of real activity is posited from the very start. We construct a model of inflation and growth that distinguishes between the properties of various qualitatively different inflation regimes. It is then shown how some of these regimes, by undermining confidence in various nominal contracts that are central to the process of accumulation in a monetary production economy, can adversely affect growth.
\end{abstract}

JEL Classification Codes: E31, O41, E12

Keywords: Inflation, strato-inflation, hyper-inflation, indexation, conflicting claims, uncertainty, growth. 


\section{Introduction}

The idea that inflation may have adverse real effects on the economy is by no means new. In orthodox theory, the possibility has been discussed at least since the early 1970s. Milton Friedman’s Nobel Lecture (Friedman, 1977) was one of the first works to discuss the issue theoretically. ${ }^{1}$ Famous for his analysis of the natural rate of unemployment and vertical long-run Phillips curve, Friedman (1977) drew attention to the seemingly positive slope of the Phillips Curve during the 1970s stagflation episode. According to Friedman, the conditions for a vertical Phillips are disrupted when an economy transitions from a low inflation environment to one of higher inflation rates. During the transition period - which can last for decades - inflation rates tend to become more volatile, meaning that the economy faces increased uncertainty (Friedman, 1977: 465-466). ${ }^{2}$ This higher volatility is likely to have adverse real effects. For instance, increased volatility of inflation rates reduce the economy's efficiency since agents find it more difficult to "extract the signal about relative prices from the absolute prices" (Lucas, 1973; 1975; Harberger, 1976 apud Friedman, 1977: 467). Friedman argued, however, that such situations tend to be transitory. Accordingly, a situation of high inflation volatility eventually leads to either hyperinflation or stabilization. A third and intermediate possibility is change in a country’s institutions that adapt to the environment of higher inflation, indexation being the clearest example of this intermediate possibility (Friedman, 1977: 468-470).

\footnotetext{
${ }^{1}$ Milton Friedman won the 1976 Nobel Prize in Economics. Friedman’s 1976 Nobel Lecture was published in 1977 by the Journal of Political Economy.

2 The impact of higher inflation on uncertainty was previously discussed by Okun (1971) (on which see Ball and Cechetti, 1990: 814).
} 
Since Friedman, various orthodox contributions have continued to analyze the real effects of inflation. ${ }^{3}$ Currently, the idea, that higher inflation leads to higher inflation variability and produces negative real effects is sufficiently well established in orthodox thought to have found its way into textbooks. ${ }^{4}$ The fact is, however, that this thinking is a better fit with Post Keynesian analysis. Central to the core of modern orthodox macroeconomics is the pre-Keynesian notion of a Classical dichotomy, according to which monetary variables are neutral with respect to the real economy in the long run. This sits uneasily with the claim that inflation can have adverse real effects over periods (per Friedman) that may extend for decades. ${ }^{5}$ Post Keynesians, however, emphasize the central role of uncertainty and money contracts in the economy. As a result, Post Keynesian theory provides a more obvious and ultimately richer framework in which to develop the idea that increasing inflation can increase uncertainty and so reduce economic growth. Specifically, Post Keynesians can argue straightforwardly that inflation volatility increases uncertainty about the future, resulting in a diminution of confidence in forecasts of the future implicit in nominal contracts and an associated rise in agent's liquidity preference that is followed by less investment and slower economic growth.

This train of thought did not pass unnoticed by earlier Post Keynesians. Weintraub (1978), for instance, lists a series of channels through which inflation could

\footnotetext{
${ }^{3}$ For example, Fischer and Modigliani (1978) provide a list of channels through which inflation might have real effects, while Ball and Cechetti (1990) introduce a distinction between short and long time horizons over which the real effects of inflation (if any) may differ.

${ }^{4}$ For instance, Carlin and Soskice (2006) present the idea that "when inflation is high it also seems to be more volatile...volatile inflation masks the economically relevant changes in relative prices and therefore distorts resource allocation. In short, volatile inflation has real effects on the economy that are hard to avoid" (Carlin and Soskice, 2006: 135).

${ }^{5}$ Witness, for example, the skepticism of real Business Cycle theorists towards the notion that "price surprises" are the source of even short-run variations in real activity.
} 
impact the economy. The list includes the fact that inflation "clouds rational long-range economic planning", "favours financial capital as against productive capital” and “induces the development of defensive speculative practices" (Weintraub, 1978:29-33 apud Carvalho, 1992: 190). It was Carvalho (1992), however, who first systemized these ideas within a Post Keynesian framework. Carvalho first reproduces the Friedmanite argument that inflation variance distorts price signals and so adversely affects the real economy. Hence for Carvalho, "differences in competitivity, market power or just plain agility in perceiving nominal changes are enough to generate real effects upon inflation” (Carvalho, 1992: 190). Subsequently, however, he emphasizes concepts with more obvious fidelity to Post Keynesian theory. He stresses the impact of inflation on uncertainty and how this unfolds in agent's investment decisions and their use of monetary contracts. In this regard, his main ideas can be summarized as follows:

The main point raised so far is that inflation heightens uncertainty. Because inflation increases uncertainty, making it more difficult to formulate hypotheses and probability relations to orient the formation of expectations and the choice of strategies, it causes more damage to those activities for which distant temporal horizons are more important. Investments in capital goods and long-term finance tend to disappear, replaced by shorter and more flexible forms of commitments that allow rerouting if some unpredicted development ensues.

(Carvalho, 1992: 191)

Unfortunately Carvalho does not introduce these concepts into existing Post Keynesian macrodynamic models in order to formally demonstrate how they affect real activity. Nor has Carvalho's thinking been incorporated into Post Keynesian macrodynamics by other authors, with the sole exception (to the best of our knowledge) 
of Oreiro and Neves (2010). ${ }^{6}$ The result is that contemporary Post Keynesian models generally ignore the potentially harmful real effects of inflation: ${ }^{7}$ no account is taken of the channels through which higher inflation might negatively impact growth by increasing uncertainty and reducing investment.

The purpose of this paper is to develop a model, based on otherwise standard conflicting-claims inflation theory and Kaleckian growth theory, that rectifies this problem. In so doing it provides a link between fundamentalist Keynesian thinking on uncertainty and liquidity preference and Kaleckian growth theory - a link that is underdeveloped in existing Kaleckian macrodynamics. ${ }^{8}$ The remainder of the paper is organized as follows. Section 2 discusses a typology of different inflation regimes in the context of a conflicting claims inflation model. In section 3, the potentially adverse real effects of inflation are explored by combining the analysis in section 2 with an extended Kaleckian growth model. Finally, section 4 offers some conclusions.

\footnotetext{
${ }^{6}$ Oreiro and Neves (2010) discuss the possibility of adverse real effects of inflation in a non-linear Post Keynesian macrodynamic model. The model proposed in this paper differs from theirs in several important respects. Oreiro and Neves (2010) posit a continuous (quadratic) relationship between the rate of accumulation and the rate of inflation, in which an increase in the rate of inflation first increases and then (beyond some threshold value) decreases the rate of growth. In our model, however, the effects of inflation on growth vary between discrete and qualitatively different inflation regimes (equilibrium inflation, stratoinflation, high inflation and hyperinflation), and our investment function posits that the rate of accumulation depends on the variance of inflation rather than its rate. Finally, we model inflation in terms of a conflicting claims process. Given the sensitivity to the wage share of the underlying growth process, this allows us to simultaneously consider the effects on growth of both variations in the wage share and the variance of inflation as strato-inflation and/or hyperinflation regimes unfold.

${ }^{7}$ For instance, Lavoie's (2014, chpt. 8) conflicting claims inflation model shows that in a wage-led economy - when neither firms nor trade unions have absolute bargaining power - higher inflation rates resulting from real wage increases are always accompanied by a higher rate of economic growth, no matter how high the inflation rate is or by how much inflation has increased (Lavoie, 2014: 554-555).

${ }^{8}$ Canonical Kaleckian growth theory acknowledges the role of animal spirits in contributing to the investment decision, but animal spirits are conventionally held constant or subject only to exogenous variation in the ensuing analysis. See, for example Lavoie (2014, chpt. 6).
} 


\section{A typology of inflation regimes}

We begin with a simple conflicting claims model of the form: ${ }^{9}$

$$
\begin{aligned}
& w=\mu\left(\omega_{w}-\omega\right) \\
& p=\varphi\left(\omega-\omega_{f}\right) \\
& w=p
\end{aligned}
$$

where $w$ is the rate of growth of nominal wages, $\omega$ is the real wage (and $\omega_{w}$ and $\omega_{f}$ are workers' and firms' preferred or target values of the real wage, respectively), ${ }^{10}$ and $p$ is the rate of inflation. The parameters $\mu$ and $\varphi$ represent the actual extent to which workers and firms (respectively) exert bargaining effort in the pursuit of their real wage targets, as distinct from their potential bargaining power denoted as $\mu_{\max }$ and $\varphi_{\max }$, respectively Implicit in this distinction between actual bargaining effort and potential bargaining power is the notion that, for various institutional and behavioral reasons, we may observe $\mu<\mu_{\max }, \varphi<\varphi_{\max }$. For example, social democratic labor market institutions that foster “social partnership” between workers, firms, and the state may temper the exercise of bargaining power relative to what would be observed under neoliberal labor market institutions that embody a "winner takes all” ethos. ${ }^{11}$ Satisficing behavior may also be an important factor in bringing about $\mu<\mu_{\max }, \varphi<\varphi_{\max }$. Hence suppose that the current wage share is deemed “close enough" to $\omega_{w}\left(\omega_{f}\right)$ by satisficing workers (firms). This

\footnotetext{
${ }^{9}$ See, for example, Rowthorn (1977) and Lavoie (2014, chpt. 8).

${ }^{10}$ Firms' target real wage is implicit in their target mark up, $\tau_{f}$, in the standard Kaleckian mark-up pricing equation $P_{f}=\left(1+\tau_{f}\right) W a$, where $P_{f}$ is firms preferred price level (based on their target mark up), $W$ is the nominal wage, and $a$ is the labor to output ratio. It follows from this mark up equation that $\frac{W}{P_{f}}=\omega_{f}=\frac{1}{\left(1+\tau_{f}\right) a}$. Note that the actual price level will result from the actual mark up consistent with the equilibrium wage share derived below that, following Kalecki (1971), will reflect the influence of workers' bargaining power.

${ }^{11}$ Of course, neoliberal labor market institutions may reduce the ability of workers to bargain, and the effects of this may more than offset any effect on the willingness of workers to bargain. See, for example, Setterfield (2006, 2007).
} 
removes the incentive to exert additional bargaining effort, which is costly, given that by hypothesis (the current wage share having been deemed "close enough" to $\omega_{w}\left(\omega_{f}\right)$ ) there is nothing to gain. Finally, trust may be an important determinant of $\mu<\mu_{\max }, \varphi<\varphi_{\max }$. Suppose, then, that trust results in workers (firms) assuming that $\omega$ will not, in future, vary "too far" from a current wage share deemed "close enough" to $\omega_{w}\left(\omega_{f}\right)$ for reasons of satisficing behavior as previously explained. This will reduce the perceived need to act pre-emptively in the current period in order to protect income shares against potential future encroachment by the other party.

It follows from equations [1] - [3] that given the initial values of the parameters $\mu$, $\varphi, \omega_{w}$, and $\omega_{f}$ the equilibrium real wage and rate of inflation can be described as:

$$
\begin{aligned}
& \omega^{*}=\frac{\mu \omega_{w}+\varphi \omega_{f}}{\mu+\varphi} \\
& p^{*}=\frac{\mu \varphi\left(\omega_{w}-\omega_{f}\right)}{\mu+\varphi}
\end{aligned}
$$

These outcomes are depicted in Figure 1.

[FIGURE 1 GOES HERE]

We now augment the simple conflicting-claims model with the following behaviors:

$$
\begin{aligned}
& \Delta \mu=\mu\left(\omega_{w}-\omega^{E}\right) \quad \text { if } \quad \omega_{w}-\omega^{E}>C \\
& =0 \quad \text { if } \quad \omega_{w}-\omega^{E} \leq C \\
& \Delta \varphi=\varphi\left(\mu-\mu_{-1}\right)
\end{aligned}
$$

where $\omega^{E}$ denotes the current equilibrium value of $\omega$ and $c$ is a conventional constant. Equation [6] formally appeals to the idea that worker's bargaining behavior is satisficing 
( $\Delta \mu=0$ if $\omega_{w}-\omega^{E} \leq c$ ), but posits that workers will bargain harder - assuming that $\mu<$ $\mu_{\max }$ initially, so that such behavior is feasible - if provoked by sufficiently adverse real wage outcomes $\left(\omega_{w}-\omega^{E}>c\right)$. Equation [7], meanwhile, describes a process of retaliation by firms (again assuming the feasibility of such behavior, i.e., $\varphi<\varphi_{\max }$ initially). Taken together, equations [6] and [7] establish a leader-follower dynamic in bargaining intensity in the event that $\omega_{w}-\omega^{E}>C$.

Following Jackson and Turner (1972) and Carvalho (1992, chpt.11; 1993), we can use the augmented conflicting claims framework outlined above to develop a typology of qualitatively different inflation regimes. In this regard, it is interesting to start with the concepts of equilibrium inflation and strato-inflation proposed by Jackson and Turner (1972).

Equilibrium inflation describes a situation in which inflation rates are low and prices rise at a steady pace. ${ }^{12}$ When the inflation rate gets higher and moves beyond a certain upper boundary, social groups start to organize and mobilize in an effort to compensate for real income losses due to inflation and avoid further real income losses in the future. Strato-inflation refers to the resulting situation, in which social groups increase the intensity with which they bargain in order to maintain their real incomes, so that the rate of inflation increases. In other words:

"The process of strato-inflation is thus essentially one in which, past inflation having proceeded to the point at which major deprivation has been experienced by particular

\footnotetext{
12 Jackson and Turner's (1972, pp.22-9) conception of equilibrium inflation is closely associated with productivity growth, to which the rate of growth of real wages must be equal in order for income shares to remain constant. Since there is no technical progress in our conflicting-claims model (so that constancy of income shares requires only that $w-p=0$, or in other words, $w=p$, as in the equilibrium condition in equation [3]) we abstract from this concern in what follows.
} 
social groups, these then organize not merely for their future protection, but to recover lost ground. Retaliatory-defensive mechanisms are then built by other groups, so that the inflation accelerates” (Jackson and Turner, 1972: 34).

Based on these observations and on the augmented conflicting claims model, it is now possible to formally describe an equilibrium inflation regime and a strato-inflation regime. ${ }^{13}$ An equilibrium inflation regime is a situation in which the inflation rate is sufficiently low, say at or below a certain upper boundary $p_{s}$, at which, in conjunction with the current bargaining posture of labor $(\mu), \omega_{w}-\omega=c \Rightarrow \omega=\omega_{w}-c .{ }^{14}$ This boundary is depicted in Figure 2, where $\omega^{E}=\omega^{*}>\omega_{w}-c \Rightarrow \omega_{w}-\omega^{*}<c$. In this case, then, $\Delta \mu=\Delta \varphi=0$ in [6] and [7], and the initial equilibrium depicted in Figure $2\left(\omega^{*}, p^{*}\right)$ is indefinitely self-sustaining (ceteris paribus).

\section{[FIGURE 2 GOES HERE]}

A strato-inflation regime is then a situation in which the inflation rate surpasses the upper boundary $p_{s},{ }^{15}$ so that $\omega^{E}<\omega_{w}-c \Rightarrow \omega_{w}-\omega^{E}>c$ and conflicting claims become acute. This situation is depicted in Figure 3 where, starting from the equilibrium inflation regime depicted in Figure 2 (with $p=p^{*}$ and $\omega=\omega^{*}$ ), we assume that an initial

13 Jackson and Turner's (1972) analysis of equilibrium and strato-inflation was based on the empirical observation of the average annual rate of price inflation of a large sample of countries from 1948 to 1971 . Based on these observations, they argued that it was possible to define two clusters of non-communist countries according to their average inflation rates: equilibrium inflation countries and strato-inflation countries. The first cluster had average inflation rates around 3\% annually, whereas the second had 30\% average annual inflation. Taking into account that equilibrium inflation countries can be transformed into strato-inflation countries, it is reasonable to adapt these concepts to explain different inflation regimes within the same country over time.

${ }^{14}$ The bargaining power of labor is privileged in the definition of $p_{s}$ here because of the specific role of labor in the leader-follower dynamic in equations [6] and [7]. Note that if firms were described as initiating changes in bargaining intensity in these equations (with workers retaliating), then the bargaining posture of firms $(\varphi)$ would enter into the determination of $p_{s}$. In reality, of course, it is possible that either workers or firms will initiate a change in bargaining intensity, depending on initial conditions in the economy as a whole.

${ }^{15}$ Jackson and Turner (1972) argues that the lower boundary of strato-inflation tends to be the ceiling of equilibrium inflation (Jackson and Turner, 1972: 37). 
shock increases $\varphi$ to $\varphi^{\prime}$ thus increasing $p$ to $p^{\prime}>p_{s}$ and so reducing $\omega^{E}$ to $\omega^{\prime}<\omega_{w}-c{ }^{16}$

This will activate the dynamics in equations [6] and [7]. First, as a result of equation [6], we will observe $\Delta \mu>0$. This is captured in Figure 3 by the initial increase in $\mu$ to $\mu^{\prime}$, which will increase the rate of inflation and the wage share above $p^{\prime}$ and $\omega^{\prime}$, respectively. ${ }^{17}$ Next, as a result of equation [7], firms will retaliate to the change in workers' bargaining posture - an event that is captured in Figure 3 by the increase in $\varphi$ from $\varphi^{\prime}$ to $\varphi^{\prime \prime}$, bringing the wage share back to $\omega^{\prime}$ and further increasing the rate of inflation to $p^{\prime \prime} .{ }^{18}$ Of course, this is not the end of the story: the outcomes $\omega$ ' and $p "$ together constitute a "provisional equilibrium” (Chick and Caserta, 1997) - that is, a temporary equilibrium configuration that awaits subsequent reconfiguration as a result of dynamics that are endogenous to the system. In this case, the restoration of $\omega^{E}$ to $\omega^{\prime}<\omega_{w}-c$ will call forth a further adjustment of the bargaining posture of workers in [6], prompting further retaliation by firms in [7], and so on. These subsequent developments - as a result of which the rate of inflation, if unchecked by policymakers, ${ }^{19}$

\footnotetext{
${ }^{16}$ Note that the initiating shock could emanate from, for example, an exchange rate depreciation. For instance, Bastos (2002: 122) argues that exchange rate depreciation was the main trigger of Brazil's pricespiral experience during the 1980s and 1990s. The potential importance of exchange rate depreciation as the initiating shock draws attention to open-economy extensions of the analysis presented in this paper that are left to further research.

${ }^{17}$ Figure 3 depicts the increase in $\mu$ to $\mu^{\prime}$ as being exactly sufficient to set $\omega=\omega_{W}-c$. In practice, and assuming that workers are unable to precisely "fine tune" their bargaining strategies in accordance with the satisficing demands of their wage share aspirations, any increase in $\omega$ sufficient to satisfy $\omega \geq \omega_{w}-c$ might emerge from workers' initial response in equation [6] to $p>p_{s} \Rightarrow \omega<\omega_{W}-c$. In any event, the resulting wage share will not persist, since we have yet to consider the retaliatory behavior of firms as described in equation [7].

${ }^{18}$ Note that following the initial shock, the consecutive adjustments in $\mu$ and $\varphi$ that are depicted in Figure 3 are exactly offsetting, in the sense that the wage share $\left(\omega^{\prime}\right)$ remains constant following the adjustments in $\mu$ and $\varphi$ even as the rate of inflation increases. Obviously this need not be the case and some variation in the value of $\omega$ may occur - although by hypothesis, such variation cannot be so great as to yield $\omega_{w}-\omega^{E} \leq c$, as this would shut down the dynamics in equations [6] and [7] and the economy would no longer be in a strato-inflation regime. The possibility of an economy exiting a strato-inflation regime is addressed below. ${ }^{19}$ Due to political commitments or lack of political strength, policy-makers may be unwilling or unable to adopt policies to halt the process.
} 
will increase further and (ceteris paribus) will keep increasing as long as $\omega_{w}-\omega^{E}>c-$ are depicted by the vertical arrows in Figure 3 .

\section{[FIGURE 3 GOES HERE]}

In the preceding account, strato-inflation is presented as a disequilibrium regime. ${ }^{20}$ Jackson and Turner nevertheless stress that "the [strato-inflation] process is not unlimited, because there comes a point at which the rate of price inflation is so high that the institutional mechanisms involved can no longer function adequately" (Jackson and Turner, 1972: 34). This suggests that just as there exists a lower boundary of stratoinflation (that is also the upper boundary of equilibrium inflation), so there is also an upper boundary to strato-inflation (Jackson and Turner, 1972: 34; 37). ${ }^{21}$

Jackson and Turner admit two possibilities when the economy reaches the upper boundary of strato-inflation. The first and most common exit is the adoption of a stabilization plan that brings inflation rates down. The intense conflicting claims associated with a very high inflation rate force the government to take action by adopting a stabilization program aimed at reducing inflation.

Jackson and Turner believe that the adoption of a stabilization plan is unlikely to reduce inflation rates sufficiently to transform a strato-inflation regime into an equilibrium inflation regime. ${ }^{22}$ However, with the benefit of hindsight (specifically, experience of the neoliberal era), it now seems reasonable to suppose that the policy

\footnotetext{
${ }^{20}$ It also demonstrates that it is possible to think of equilibrium inflation regimes as locally stable but globally unstable: any shock sufficient to transform $\omega_{w}-\omega^{E} \leq c$ into $\omega_{w}-\omega^{E}>c$, and we leave the equilibrium inflation regime and enter a disequilibrium strato-inflation regime.

${ }^{21}$ Based on the experience of strato-inflationary countries like Argentina and Chile, Jackson and Turner (1972) suggest 10 percent as a floor and 50 percent as a ceiling for a strato-inflation process (Jackson and Turner, 1972: 31; 35).

${ }^{22}$ This is because "people may continue to demand a minimum rate of monetary wage or income increase as an insurance against the failure of the policy, or against discrimination in income distribution" (Jackson and Turner, 1972: 37).
} 
authorities can effectively reverse the dynamic in equation [6] (thus shutting down the accompanying retaliatory dynamic in equation [7]) by suppressing the bargaining power of workers to an extent that the economy is restored to the equilibrium inflation regime depicted in Figure 2.

A second possible exit when the inflation rate moves beyond the upper bound of strato-inflation is hyperinflation. If the government does not take action to contain inflation, then conflicting claims intensify further and inflation will keep increasing. ${ }^{23}$ As a result, the economy will exit strato-inflation, but only to settle into a hyperinflation regime. $^{24}$

However, there is also a third alternative exit from hyperinflation. As Carvalho (1992; 1993) argues, Jackson and Turner "did not seriously consider the possibilities of changing institutions to adapt to strato-inflation in order to institutionalize conflict in an analogous manner ... to equilibrium inflation” (Carvalho, 1993: 66). In other words, Jackson and Turner "failed to recognize the possibility of reaching a new kind of equilibrium at high rates of inflation” (Carvalho, 1993: 64). Based especially on the Brazilian experience of the 1960s to the 1980s, Carvalho suggests that when inflation rates get sufficiently high, one possible response is institutional change in order to adapt

\footnotetext{
${ }^{23}$ Jackson and Turner (1972) stress that a country could move from strato-inflation to hyperinflation due to a shock, like a war or rebellion. However, they emphasize that the most important cause is the "political incapacity of government to dominate the forces pushing towards that condition" (Jackson and Turner, 1972: 54). Government's political capacity is also seen as crucial to prevent an economy from moving from equilibrium inflation to strato-inflation (Ibid).

${ }^{24}$ Jackson and Turner (1972) point out that hyperinflation is necessarily a transitory condition (Jackson and Turner, 1972: 54). Due to its destructive social and economic impacts, a hyperinflation regime cannot last indefinitely, and may not even last for very long.
} 
to high inflation. This would then create a situation of equilibrium with high inflation rates or in other words, a high inflation regime. ${ }^{25}$

When inflation rates are high, contracts - especially forward contracts - are affected because agents lose confidence in the unit of account. If contracts are indexed, agents will gain at least partial protection against inflation and this will reduce uncertainty. Therefore, "the main feature of a high inflation regime is the creation of a widespread system of contracts denominated in a unit of account other than the legal tender of the economy" (Carvalho, 1993: 67). More precisely, a high inflation regime is characterized by the "widespread practice of indexation of contracts" (Carvalho, 1993: $67)$.

Indexation does not solve the economy's conflicting claims. For instance, not all contracts are indexed in the same way (Carvalho, 1992: 198; Carvalho: 1993: 66). In this sense, the possibility remains that the economy will move from a high inflation regime to a hyperinflation regime. ${ }^{26}$ Indexation can bring some stability, however, and an economy can spend a long period of time in a high inflation regime. It describes a situation in which "agents see no reason (or no possibility) to change their chosen conflict strategies" (Carvalho, 1993, p.66). As a result, the dynamic in equation [6] (and hence that in equation [7]) is shut down, and the economy settles into a constant (albeit high) equilibrium rate of inflation.

\footnotetext{
${ }^{25}$ Carvalho (1992; 1993) believes that the concept of strato-inflation is flawed and should be replaced by the concept of a high-inflation regime (Carvalho, 1993: 66-7). We argue that these are not rival concepts and that as demonstrated in the text, they can be reconciled as part of a more extesnive suite of qualitatively different inflation regimes.

${ }^{26}$ See Carvalho (1992) for details.
} 
In terms of the conflicting claims framework developed earlier, a high inflation regime can be shown to emerge for any one of several reasons. ${ }^{27}$ First, workers may cease to find themselves in the interior of their bargaining possibility set $\left(\mu<\mu_{\max }\right)$. In this case, $\mu=\mu_{\max }$ and there is no possibility of further increases in $\mu$ emanating from the dynamic in [6]. ${ }^{28}$ Second, as suggested earlier, the dynamics of strato-inflation may involve some change in the equilibrium value of $\omega$. Should this result in $\omega_{w}-\omega^{E} \leq c$, workers will have no reason to further intensify their bargaining posture, and the dynamics in [6] and [7] will shut down. ${ }^{29}$ Third, experience of strato-inflation may provoke:

institutional changes [that] ... reorient the opposing forces not towards a kind of final settlement, ... but to compliance with rules of conflict that limit damages and increase the predictability of outcomes, allowing economic life to recover some measure of stability while conflict goes on.

(Carvalho, 1993, p.66)

As previously noted, this conflict-amelioration is the essential purpose of indexation.

Hence suppose we amend the simple conflicting claims model introduced earlier as

follows:

$$
\begin{gathered}
w=\lambda p_{-1}+\mu\left(\omega_{w}-\omega\right) \\
p=\beta w_{-1}+\varphi\left(\omega-\omega_{f}\right)
\end{gathered}
$$

\footnotetext{
${ }^{27}$ In each case, the inflation rate associated with the high inflation regime can be considered the upper boundary of strato-inflation. The upper boundary of strato-inflation can be lower or higher depending on sundry characteristics . For instance, the degree of organization and strength of trade unions is an important factor, because it ultimately determines $\mu_{\max }$.

${ }^{28}$ Note that for values of $\mu_{\max }$ sufficiently small, the economy will exit the disequilibrating dynamics imposed by [6] and [7] and settle at a rate of inflation sufficiently low in value to merit description as an equilibrium inflation regime. This possibility draws attention to the fact that in order to make the typology of inflation regimes outlined here meaningful, the dynamics of inflation must be characterized by a sufficiently strong wage push channel, resulting from sufficiently strong potential bargaining power of workers, $\mu_{\max }$. Otherwise, the economy will never exit from an equilibrium inflation regime, rendering the possibility of strato-inflation, hyperinflation and high inflation regimes moot.

${ }^{29}$ This possibility is implicit in Jackson and Turner's (1972, pp.38, 39) discussion of strato-inflation, in which the real wage is assumed to increase over time.
} 


$$
w=w_{-1}=p=p_{-1}
$$

and assume, following Carvalho (1993), that indexation - the inclusion of the lagged inflation and wage growth terms in equations [1a] and [2a], respectively - suffices to shut down the dynamics in [6] and [7]. The equilibrium solution of the model is now given by:

$$
\begin{aligned}
& \omega^{*}=\frac{(1-\beta) \mu \omega_{w}+(1-\lambda) \varphi \omega_{f}}{(1-\beta) \mu+(1-\lambda) \varphi} \\
& p^{*}=\frac{\mu \varphi\left(\omega_{w}-\omega_{f}\right)}{(1-\beta) \mu+(1-\lambda) \varphi}
\end{aligned}
$$

As long as the process of indexation is incomplete (i.e., $\lambda<1$ and/or $\beta<1$ ), ${ }^{30}$ the result will be a well-defined equilibrium rate of inflation (as in [5a]) similar to that illustrated in Figure 2, but at a higher rate of inflation. ${ }^{31}$

In sum, the preceding discussion of different inflation regimes can be formally summarized as follows:

\section{Equilibrium inflation regime:}

$$
p \leq p_{s} \Rightarrow \omega_{w}-\omega^{E} \leq c
$$

and

$$
\Delta \mu=\Delta \varphi=0
$$

Strato-inflation regime:

$$
p_{s}<p \leq p_{h} \Rightarrow \omega_{w}-\omega^{E}>c
$$

\footnotetext{
${ }^{30}$ Variation in bargaining intensity may plausibly give rise to variation in the size of $\lambda$ and $\beta$. We abstract from this possibility for the sake of simplicity, taking both $\lambda$ and $\beta$ as given.

${ }^{31}$ Note that incomplete indexation - and hence a high inflation regime - does not involve "fooling” effects on the part of either workers or firms: in equilibrium, $w=p$ so that the real wage (together with the wage share in [4a]) remain constant over time. See also Cornwall (1983).
} 
and

$$
\Delta \mu, \Delta \varphi>0
$$

where $p_{h}$ is the upper boundary of strato inflation.

Finally, when inflation exceeds the upper boundary of strato-inflation $\left(p>p_{h}\right)$, then there are three possibilities: 1) stabilization; 2) a hyperinflation regime; and 3) a high inflation regime. $^{32}$

\section{The adverse real effects of inflation: a Post-Keynesian view}

i) A Post-Keynesian model of the adverse real effects of inflation

The general theme in this section is that increasing inflation (as in a strato- or hyper-inflation regime) raises the variance of, and hence uncertainty about, the rate of inflation which, in turn, creates uncertainty about the future real value of commitments written into money contracts. The latter are, of course, a central feature of activity in a monetary-production economy that is subject to fundamental uncertainty. Increasing inflation can therefore be disruptive to real activity by reducing confidence in the outcomes associated with money contracts. Crucially for the analysis that follows, these include:

- money contracts used to commit to the sales of final output - these are important for reducing uncertainty about expected future sales, and hence the expected future rate of return on physical capital in the real sector

\footnotetext{
${ }^{32}$ Friedman (1977) did not employ the concept of strato-inflation. However, as noted in the previous section, he did suggest that there were three possibilities when an economy transitions from lower inflation to higher inflation rates: 1) stabilization; 2) hyperinflation; and 3) indexation (Friedman, 1977: 468-470).
} 
- money contracts used to set up relationships between creditors and debtors - these are important for reducing uncertainty about the rate of return to financial capital that is, in turn, used to finance investment in physical capital.

In the event that increasing inflation causes an increase in inflation variance, the adverse effects of increased inflation uncertainty on the value of money contracts, working through the channels highlighted above, can be expected to diminish the animal spirits of industrial and financial capitalists alike, diminishing the prospects for growth.

Formally, we begin with a simple Kaleckian growth model of the form:

$$
\begin{aligned}
& g=\gamma_{1}+\gamma_{2} u \\
& u=\frac{r}{\pi} \\
& r=\frac{1}{S_{\pi}} g \\
& \Rightarrow g^{*}=\frac{\gamma_{1} s_{\pi} \pi}{S_{\pi} \pi-\gamma_{2}}
\end{aligned}
$$

where $g=I / K$ is the rate of growth, $u=Y / K$ is the rate of capacity utilization, $r$ and $\pi=(1$ $-\omega)$ are the rate of profit and the profit share of income, respectively, $s_{\pi}$ is the propensity to save out of profits, and $\gamma_{1}, \gamma_{2}>0$. Notice that it follows form equation (11) that:

$$
\frac{d g^{*}}{d \pi}=\frac{-\gamma_{1} \gamma_{2}}{\left(s_{\pi} \pi-\gamma_{2}\right)^{2}}<0
$$

In other words, the model in equations (8) - (11) displays the familiar wage-led property associated with the canonical Kaleckian growth model (Lavoie, 2014, chpt.6).

We now write: 


$$
\sigma_{p}^{2}=c+\delta . \Delta p
$$

where $\sigma_{p}^{2}$ is the variance of the inflation rate and $c, \delta>0,{ }^{33}$ and:

$$
\alpha=f\left(\sigma_{p}^{2}\right), f^{\prime}<0
$$

where $\alpha$ denotes the animal spirits of industrial and financial capitalists. Equation [12] posits that the variance of inflation is increasing in $\Delta p$, the rate of change of inflation (per Friedman, 1977). According to equation [13], meanwhile, an increase in inflation variance (and hence inflation uncertainty) increases both borrower’s and lender’s risk, diminishing the animal spirits (and raising the liquidity preference) of both industrial and financial capitalists.

Finally, our model is completed by the expressions:

$$
\begin{array}{ll}
\gamma_{1}=h(\alpha), & h^{\prime}>0 \\
\gamma_{2}=k(\alpha), & k^{\prime}>0
\end{array}
$$

Equations [14] and [15] suggest that the adverse effect of inflation uncertainty on animal spirits in [13] will affect investment spending in [8], and hence the equilibrium rate of growth in [11], through two channels. Equation [14] captures the direct channel, through which inflation uncertainty diminishes the animal spirits of industrialists and hence

\footnotetext{
${ }^{33}$ Note that in equation [12], inflation variance is a positive constant even when $\Delta p=0$ - i.e., when the economy is in either an equilibrium or a high inflation regime. This allows for the possibility of exogenous shocks to the inflation rate. In other words, we characterize inflation in an equilibrium or high inflation regime as:

$$
p=p^{E}+\varepsilon
$$

where $p^{E}$ denotes the constant rate of inflation consistent with any given equilibrium or high inflation regime and $\varepsilon \sim N(0, c)$. Given the usual assumptions about $\varepsilon$, it follows that in either an equilibrium or a high inflation regime:

$$
\sigma_{p}^{2}=\sigma_{p^{E}}^{2}+\sigma_{\varepsilon}^{2}=c
$$
}


reduces the planned rate of investment. Equation [15] captures the indirect channel. First note that by substituting equation (9) into equation (8), we obtain:

$$
g=\gamma_{1}+\frac{\gamma_{2}}{\pi} r
$$

The influence of $r$ on $g$ (given $\pi$ ) in equation (8a) is accounted for by the principle of increasing risk (Kalecki, 1937): firms borrow in order to finance investment expenditures, and in order to appease lenders (given that the decision-making environment is one of uncertainty), firms first need to generate and retain sufficient profits. This means that ceteris paribus, higher profits are required to facilitate the borrowing necessary to finance additional planned investment expenditures - hence the direct relationship between the rates of profit and investment seen in [8a]. But the extent to which any given rate of profit can be successfully leveraged into a new flow of finance (and hence actual investment), as reflected in the size of $\gamma_{2}$, depends (inter alia) on financiers perception of lender's risk, as reflected in their animal spirits. Hence a diminution of the latter will reduce $\gamma_{2}$ and diminish investment spending, ceteris paribus. $^{34}$

We can now illustrate the adverse real effects that result from the economy leaving an equilibrium or high inflation regime and entering into a strato- or hyperinflation regime through the interaction of equations [11] - [15]. The key characteristic of either strato- or hyper-inflation is their disequilibrium character, as a result of which $\Delta p>0$. As is obvious from equation [12], this means that entering a strato- or hyper-

\footnotetext{
${ }^{34}$ Carvalho (1992) notes that according to Feijó (1991) (and following A.D.Bain), "inflation also affects interest rates and the profile of long-term finance to the detriment of long-lived investments" (Carvalho, 1992: 190). There may, then, be financial channels other than those outlined above through which sufficiently high inflation can adversely affect investment.
} 
inflation regime will raise $\sigma_{p}^{2}$, which will diminish $\alpha$ in equation [13] and hence both $\gamma_{1}$ and $\gamma_{2}$ in equations [14] and [15]. The final result of these developments will therefore be a drop in the equilibrium rate of growth in [11]. Formally:

$$
\begin{aligned}
\frac{d g^{*}}{d \Delta p} & =\left[\frac{\partial g^{*}}{\partial \gamma_{1}} \frac{d \gamma_{1}}{d \alpha}+\frac{\partial g^{*}}{\partial \gamma_{2}} \frac{d \gamma_{2}}{d \alpha}\right] \frac{d \alpha}{d \sigma_{p}^{2}} \frac{d \sigma_{p}^{2}}{d \Delta p} \\
& =\left[\frac{s_{\pi} \pi\left(\left[s_{\pi} \pi-\gamma_{2}\right]+\gamma_{1}\right)}{\left(s_{\pi} \pi-\gamma_{2}\right)^{2}}\right] \cdot h^{\prime} . f^{\prime} \cdot \delta<0
\end{aligned}
$$

given the Keynesian stability condition $\left(s_{\pi} \pi-\gamma_{2}>0\right)$ and where, for the sake of simplicity, we assume that $h^{\prime}=k^{\prime}$. Note that the result in [16] suggests not only that entering strato- or hyper-inflation will adversely affect growth, but that these problems may intensify as strato- or hyper-inflation develops (or as the economy transitions from strato- to hyper-inflation), if ongoing strato- or hyper-inflation (or the transition from strato- to hyper-inflation) is associated with an increase in $\Delta p$, so that inflation accelerates rather than simply increasing steadily.

The analysis above presents equilibrium inflation and high inflation regimes as equivalents in terms of their benign effects on growth (because both involve $\Delta p=0$ ), despite the fact that they will involve quantitatively different (constant equilibrium) rates of inflation. This draws to attention the fact that a high inflation regime can be interpreted as a second best equilibrium inflation regime. ${ }^{35}$ Put differently, an economy experiencing

\footnotetext{
${ }^{35}$ A high inflation regime is identified as second best by Carvalho (1993: 66). One of the reasons is that, thanks to indexation, shocks that increase inflation will propagate into permanent increases in the equilibrium rate of inflation. This will not occur in an equilibrium inflation regime, where shocks will dissipate and the economy will return to its previous equilibrium inflation rate. Moreover, it is much harder to adopt a stabilization plan in a high-inflation regime than in a strato-inflation regime. In a high-inflation regime, it is necessary to de-index the economy in order to institute stabilization. As prices are not perfectly indexed and readjustments are asynchronous, it is very hard to de-index without causing losses to sundry social groups. These groups will pressure for readjustments that can cause an inflation upsurge and reindexation.
} 
a high inflation regime can nevertheless experience high economic growth rates, as was the case in Brazil between 1964 and 1980. This, in turn, suggests a potentially important and marked contrast between high inflation regimes and orthodox inflation targeting regimes (in which demand-led growth is sacrificed in favor of reduced inflation in the mistaken belief that growth is supply-led and therefore invariant with respect to demand formation conditions). Equilibrium and high inflation regimes are also similar in that they are potentially unstable. The global instability of an equilibrium inflation regime was remarked upon earlier. In a high inflation regime, meanwhile, while positive inflation shocks are generally incorporated into a new, higher equilibrium rate of inflation through the mechanism of indexation, if positive inflation shocks become too frequent, the conflict-ameliorating role of indexation can break down. This can occur because of the discrete time intervals involved in adjusting indexed wages: if sufficiently many adverse shocks occur within these intervals, workers may grow impatient with the indexation process as an institutional guarantor of their standard of living. ${ }^{36}$ If this occurs, then with the condition $\omega_{w}-\omega^{E}>c$ satisfied, the economy will reenter the disequilibrium dynamics of strato- or even hyper- inflation as the effects of equations [6] and [7] reassert themselves.

ii) Assessing the marginal impact on growth of the transition to a strato-inflation regime

\footnotetext{
${ }^{36}$ Taylor (1994) develops a discrete-time model to analyze the relationship between indexation and the acceleration of inflation. He argues that "with an annual rate of up to 30 percent (say), workers may accept yearly readjustment, but if inflation is much more rapid, they are likely to press for semiannual or quarterly contracts. At 100 percent per year (just under 6 percent per month), monthly readjusments may come into play”(Taylor, 1994: 88). He then shows that this shortening of the indexation period causes inflation to accelerate.
} 
The analysis that follows is based in the first instance on an economy that is assumed to have just transitioned from an equilibrium inflation regime into stratoinflation. The question addressed is: what are the overall effects of this initial transition on growth, bearing in mind that it involves an increase in inflation (since entering a strato-inflation regime means that $\Delta p>0$ by hypothesis) and an accompanying decrease in the wage share of income (since entering a strato-inflation regime also involves the transformation of an equilibrium wage share, such that $\omega^{E}>\omega_{W}-c$, into a provisional equilibrium wage share such that $\left.\omega^{E}<\omega_{w}-c\right)$ ?

As previously demonstrated, the initial increase in inflation as the economy enters strato-inflation will retard the rate of growth. Since the underlying Kaleckian growth model is wage-led, the accompanying reduction in the wage share will also retard growth. The unambiguous result of entering a strato-inflation regime, then, is that the rate of growth will fall: both the marginal impact on growth of the initial increase in inflation and the marginal impact on growth of the accompanying drop in the wage share are negative. This is illustrated in Figure 4, which is essentially an extension of Figure 8.4 in Lavoie (2014, p.555).

\section{[FIGURE 4 GOES HERE]}

The top right quadrant of panel (a) of Figure 4 depicts an economy that is initially in an equilibrium or high inflation regime, with an equilibrium rate of inflation $p^{*}<p_{s}$, an equilibrium wage share $\omega^{*}>\omega_{W}-c$, and $\Delta p=0$, as previously illustrated in Figure 2. Suppose now that a shock to $\varphi$ disturbs this environment, raising $p$ and lowering $\omega$ so as to activate the disequilibrating dynamics in equations [6] and [7], as in Figure 3. These events are captured in the top right quadrant of panel (a) by the initial transition to the 
new, higher, provisional equilibrium rate of inflation $p^{\prime}$ and accompanying provisional equilibrium wage share $\omega^{\prime}$. The consequences of this initial transition to strato-inflation are then captured in the three remaining quadrants of panel of (a). The top left quadrant shows that at the instant at which the figure is drawn, the new equilibrium rate of inflation $p^{\prime}$ is associated with an increase in inflation of size $\Delta p_{1}=p^{\prime}-p^{*}>0$ which, in the bottom left quadrant of panel (a), is shown to decrease the rate of growth from $g^{*}$ (associated with $\Delta p=0$ in the previously prevalent equilibrium inflation regime) to $g_{p}^{\prime} \cdot{ }^{37}$ Meanwhile, the bottom right quadrant of panel (a) shows that the decrease in the wage share brought about initially by the transition to strato-inflation is associated with an additional decrease in the rate of growth from $g^{*}$ (associated with $\omega^{*}$ in the previously prevalent equilibrium inflation regime) to $g_{\omega}^{\prime}$, as a result of the wage-led properties of the growth process. Panel (b) of Figure 4 then illustrates the overall impact on the growth rate from one period to the next of the adjustments associated with the transition to stratoinflation captured in panel (a). The economy will arrive at point A, where $g=g_{A}^{* *}<g^{*}=g_{-1}$ and $g^{* *}=g^{*}-\left(g^{*}-g_{p}^{\prime}\right)-\left(g^{*}-g_{\omega}^{\prime}\right)=g_{p}^{\prime}+g_{\omega}^{\prime}-g^{*} \cdot 38$

\footnotetext{
${ }^{37}$ Note that the decrease in growth depicted in the bottom left quadrant of panel (a) is associated with $\Delta p>0$ at $p^{\prime}$, and not with the value of $p^{\prime}$ per se. By hypothesis, we will observe $\Delta p>0$ subsequently (at consecutively higher rates of inflation) because the economy has entered a strato-inflation regime. Were the transition from $p^{*}$ to $p^{\prime}$ representative of no more than a change from one rate of inflation to another (higher) rate of inflation within an equilibrium inflation regime, then $\Delta p>0$ would be transitory and the reduction in growth shown in the bottom left quadrant of panel (a) would be similarly transitory - part of a disequilibrium adjustment or traverse path that would eventually see the economy settle down at the new rate of growth $g_{\omega}^{\prime}$ resulting exclusively from the wage-led properties of the model.

${ }^{38}$ In keeping with the analysis in Lavoie (2014), the model does not explicitly take into account possible feedback effects from net variations in the rate of growth in panel (b) to the intensity of bargaining (reflected in the size of $\mu$ and $\varphi$ ) in panel (a). This is done for the sake of simplicity, but the potential for simultaneous interaction between conflicting-claims inflation dynamics and Kaleckian growth dynamics (on which, see Cassetti, 2002) points to one obvious avenue for extension of the model presented in this paper in future research.
} 
We might also inquire into the marginal effects on growth of subsequent continuance of the period-to-period increases in inflation characteristic of a stratoinflation regime. ${ }^{39}$ The question we must now address is: what are the overall effects on growth of a further increase in inflation, bearing in mind that this may or may not be accompanied by further change in the wage share of income? ${ }^{40}$

In fact, further increase in inflation as the economy continues to experience stratoinflation may or may not further retard the rate of growth, depending on both: a) whether or not inflation accelerates; and b) the sign and size of the accompanying change in the wage share (if any). First, note that the marginal effect on growth (ceteris paribus) of an increase (decrease) in $\Delta p$ will be negative (positive), whereas the marginal effect on growth (ceteris paribus) of an increase (decrease) in $\omega$ will be positive (negative), ${ }^{41}$ due to the wage-led property of the Kaleckian growth process. A multitude of possible outcomes present themselves, therefore, depending on the precise signs of $\Delta(\Delta p)$ and $\Delta \omega$ that accompany the continuance of strato-inflation form period to period. The various scenarios that can arise, and their overall effects on the provisional equilibrium rate of growth, are summarized in Table 1 . Note that in two of the scenarios reported in Table 1 , the overall effect on growth of the continuance of strato-inflation is ambiguous. Figure 5

\footnotetext{
${ }^{39}$ The analysis that follows serves equally as an assessment of the marginal impact on growth of the subsequent onset of hyperinflation, since both strato- and hyper-inflation regimes involve repeated operation of the dynamics in equations [6] and [7] that are central to the results below.

${ }^{40}$ The reader is referred back to the earlier discussion of the behavior of the wage share in Figure 3, where it was noted that the assumed constancy of the wage share (which is sufficient but not necessary to maintain the condition $\omega_{w}-\omega^{E}>c$ and hence the disequilibrium dynamics of strato/hyper-inflation in [6] and [7]) may not materialize. The wage share may increase (within bounds), decrease, or stay the same as the rate of inflation increases beyond $p^{\prime \prime}$ in Figure 3, without violating the condition $\omega_{w}-\omega^{E}>c$.

${ }^{41}$ As previously noted, the ongoing increases in inflation associated with the continuation of strato-inflation may be accompanied by increases in the wage share, as long as any provisional equilibrium value of $\omega$ so established satisfies the condition $\omega_{W}-\omega^{E}>C$.
} 
illustrates one of these scenarios, in which an acceleration of inflation is accompanied by an increase in the wage share.

\section{[TABLE 1 AND FIGURE 5 GO HERE]}

The top right quadrant of panel (a) in Figure 5 depicts a continuation of the stratoinflation regime initiated in Figure 4, with the disequilibrating dynamics in equations [6] and [7] causing an increase in the provisional equilibrium rate of inflation from $p^{\prime}$ to $p^{\prime \prime}$, and an accompanying increase in the provisional equilibrium wage share from $\omega^{\prime}$ to $\omega^{\prime \prime} \leq \omega_{w}-c<\omega^{*}$. The consequences of these developments are then captured in the three remaining quadrants of panel of (a). The top left quadrant shows that at the instant at which the figure is drawn, the new provisional equilibrium rate of inflation $p$ " is associated with an increase in inflation of size $\Delta p_{2}=p^{\prime \prime}-p^{\prime}>p^{\prime}-p^{*}=\Delta p_{1}$ which, in the bottom left quadrant of panel (a), is shown to decrease the rate of growth from $g^{* *}$ (associated with the provisional equilibrium outcomes depicted in Figure 4) to $g_{p} .42$ Meanwhile, the bottom right quadrant of panel (a) shows that the increase in the wage share brought about by the dynamics in [6] and [7] is associated with an increase in the rate of growth from $g^{* *}$ to $g_{\omega}^{\prime \prime}$, as a result of the wage-led properties of the growth process.

Panel (b) of Figure 3 then illustrates the overall impact on the growth rate from one period to the next of the adjustments associated with the continuation of stratoinflation captured in panel (a). In the first scenario, $g=g_{A}^{* * *}=g^{* *}=g_{-1}$ at point A. This will occur if, in panel (a), the marginal impact of accelerating inflation on growth is

\footnotetext{
${ }^{42}$ Note once again that the decrease in growth depicted in the bottom left quadrant of panel (a) is associated with $\Delta p_{2}>\Delta p_{1}$ at $p^{\prime \prime}$, and not with the value of $p^{\prime \prime}$ per se.
} 
exactly offset by the marginal impact of a higher wage share on growth (i.e., $\left.g_{\omega}^{\prime \prime}-g^{* *}=g^{* *}-g_{p}^{\prime \prime}\right)$. In the second scenario, $g=g_{B}^{* * *}>g^{* *}=g_{-1}$ at point B. This will occur if, in panel (a), the marginal impact of accelerating inflation on growth is more than offset by the marginal impact of a higher wage share on growth (i.e., $g_{\omega}^{\prime \prime}-g^{* *}>g^{* *}-g_{p}^{\prime \prime}$ ). In the final scenario, $g=g_{C}^{* * *}<g^{* *}=g_{-1}$ at point C. This will occur if, in panel (a), the marginal impact of accelerating inflation on growth exceeds the marginal impact of a higher wage share on growth (i.e., $g_{\omega}^{\prime \prime}-g^{* *}<g^{* *}-g_{p}^{\prime \prime}$ ). As panel (b) of Figure 5 makes clear, all of these outcomes will result in final rates of growth at the end of the adjustment between periods depicted in Figure 5 that are less than $g^{*}$, the rate of growth associated with the initial equilibrium inflation regime. This is a result of the wage-led property of the growth process, coupled with the fact that the wage share must lie below $\omega^{*} \geq \omega_{W}-c$ in order for the economy to be experiencing strato-inflation. The greater point that emerges from panel (b), however - and still more forcefully from the results reported in Table 1 - is that the observed rate of growth can be expected to fluctuate from period to period during a strato-inflation regime. Taken together, the nominal and real outcomes associated with strato-inflation are suggestive of a highly volatile macroeconomic regime.

\section{Conclusions}

Mainstream macroeconomists have long maintained that inflation can adversely affect real economic performance. These claims emanate from supply-side models in which (at least in the long run) money is neutral - which likely accounts for the lack of 
attention they have received from Post Keynesians. On second thoughts, however, there is something ironic about all this. The possibility that inflation - a monetary phenomenon - can have real effects seems counter-intuitive in models in which money is no more than a "veil" over de facto barter relations. It seems more likely that inflation could have adverse real effects in a monetary-production economy, where money plays a fundamental role as a unit of account and store of value and there is no straightforward separation of the monetary from the real.

Motivated by this observation, the purpose of this paper has been to formalize a Post Keynesian macrodynamic system in which inflation can have adverse real effects. Starting with the work of Jackson and Turner (1975) and Carvalho (1992, 1993), we identify a variety of qualitatively different inflation regimes that can be represented as either equilibrium or disequilibrium outcomes in a conflicting-claims model of inflation. We then show how disequilibrium inflation regimes (strato-inflation and hyperinflation) can adversely affect growth, by linking increasing inflation to a higher inflation variance, increased uncertainty, and hence diminished animal spirits on the parts of both borrowers and lenders. In other words, in the context of disequilibrium inflation regimes, we suggest the existence of an inflation effect on growth that has so far been neglected in Kaleckian growth models. Our results provide an extension of existing Post Keynesian macrodynamics that may enhance the applicability of the latter to economies, including many of those in South America, that have struggled historically to combat inflationary pressures even as they have sought to foster growth and economic development. 


\section{References}

Ball, L. and S.G. Cechetti (1990) "Inflation and Uncertainty at Short and Long Horizons,” Brookings Papers on Economic Activity, 1, 215-54.

Bastos, C. (2002) Price Stabilization in Brazil: A Critical Review and a Classical Interpretation for an Indexed Nominal Interest Rate Economy. Unpublished Ph. D. Dissertation, New School University.

Carlin, W. and D. Soskice (2006) Macroeconomics: Imperfections, Institutions and Policies, Oxford: Oxford University Press.

Carvalho, F (1992) Mr. Keynes and the Post Keynesians: Principles of Macroeconomics for a Monetary Production Economy, Aldershot, Edward Elgar.

Carvalho, F. (1993) "Strato-inflation and High Inflation: the Brazilian Experience," Cambridge Journal of Economics, 17, 63-78.

Cassetti, M. (2002) "Conflict, Inflation, Distribution and Terms of Trade in the Kaleckian Model," in M. Setterfield (ed.) The Economics Of Demand-Led Growth: Challenging the Supply-side Vision of the Long Run, Cheltenham, Edward Elgar.

Chick, V. and M. Caserta (1997) "Provisional Equilibrium and Macroeconomic Theory," in P. Arestis, G. Palma and M. Sawyer (eds) Markets, Unemployment and Economic Policy: Essays in Honour of Geoff Harcourt, Vol. II, London, Routledge

Cornwall, J. (1983) The Conditions for Economic Recovery, Oxford, Martin Robertson.

Feijó, C. (1991) Economic Growth and Inflation in Brazil in he 1970s: a Post-keynesian Interpretation, unpublished $\mathrm{PhD}$ dissertation, University of London.

Fischer, S. and F. Modigliani (1978) "Towards an Understanding of the Real Effects and Costs of Inflation,” Weltwirtschaftliches Archiv, 114, 810-33.

Friedman, M. (1977) “Nobel Lecture: Inflation and Unemployment,” Journal of Political Economy, 85, No. 3, 451-472.

Harberger (1976) “Inflation.” in R.M. Hutchins and M.J. Adler (eds) The Great Ideas Today, Chicago, Encyclopaedia Britannica.

Jackson, D. and H. Turner (1972) "Inflation, Strato-inflation and Social Conflict” in Jackson, D., H. Turner and F. Wilkinson Do Trade Unions Cause Inflation?, Department of Applied Economics, University of Cambridge, Occasional Paper 56, Cambridge University Press.

Kalecki, M. (1937) “The Principle of Increasing Risk,” Economica, 4, 440-447. 
Kalecki, M. (1971) “Costs and Prices,” in Selected Essays on the Dynamics of the Capitalist Economy, Cambridge, Cambridge University Press

Lavoie, M. (2014) Post-Keynesian Economics: New Foundations, Cheltenham, Edward Elgar

Lucas, R. (1973) "Some International Evidence on Output-Inflation Tradeoffs." American Economic Review, 63, 326-34.

Lucas, R. (1975) "An Equilibrium Model of the Business Cycle." Journal of Political Economy, 83, no. 6, 1113-44.

Okun, A. (1971) “The Mirage of Steady Inflation.” Brookings Papers on Economic Activity, 2, 486- 98.

Oreiro, J.L. and A.L. Neves (2010). “Acumulação de Capital, utilização da capacidade produtiva e inflação: uma análise a partir de um modelo pós-keynesiano não linear,” Economia e Sociedade, 19, 1 (38), 1-28.

Rowthorn, R.E. (1977) “Conflict, Inflation and Money,” Cambridge Journal of Economics, 1, 215-39.

Setterfield, M. (2006) "Balancing the Macroeconomic Books on the Backs of Workers: a Simple Analytical Political Economy Model of Contemporary US Capitalism,” International Journal of Political Economy, 35, 46-63. (Erratum, International Journal of Political Economy, 37, 4, 104 (2008-09).)

Setterfield, M. (2007) “The Rise, Decline and Rise of Incomes Policies in the US During the Post-War Era: An Institutional-Analytical Explanation of Inflation and the Functional Distribution of Income,” Journal of Institutional Economics, 3, 127-46.

Taylor, L. (1994). Income Distribution, Inflation and Growth: lectures on structuralist macroeconomic theory, Cambridge: MIT Press.

Weintraub, S. (1978) Capitalism's Inflation and Unemployment Crisis, Reading: Addison-Wesley. 
Figure 1: Conflicting-claims inflation

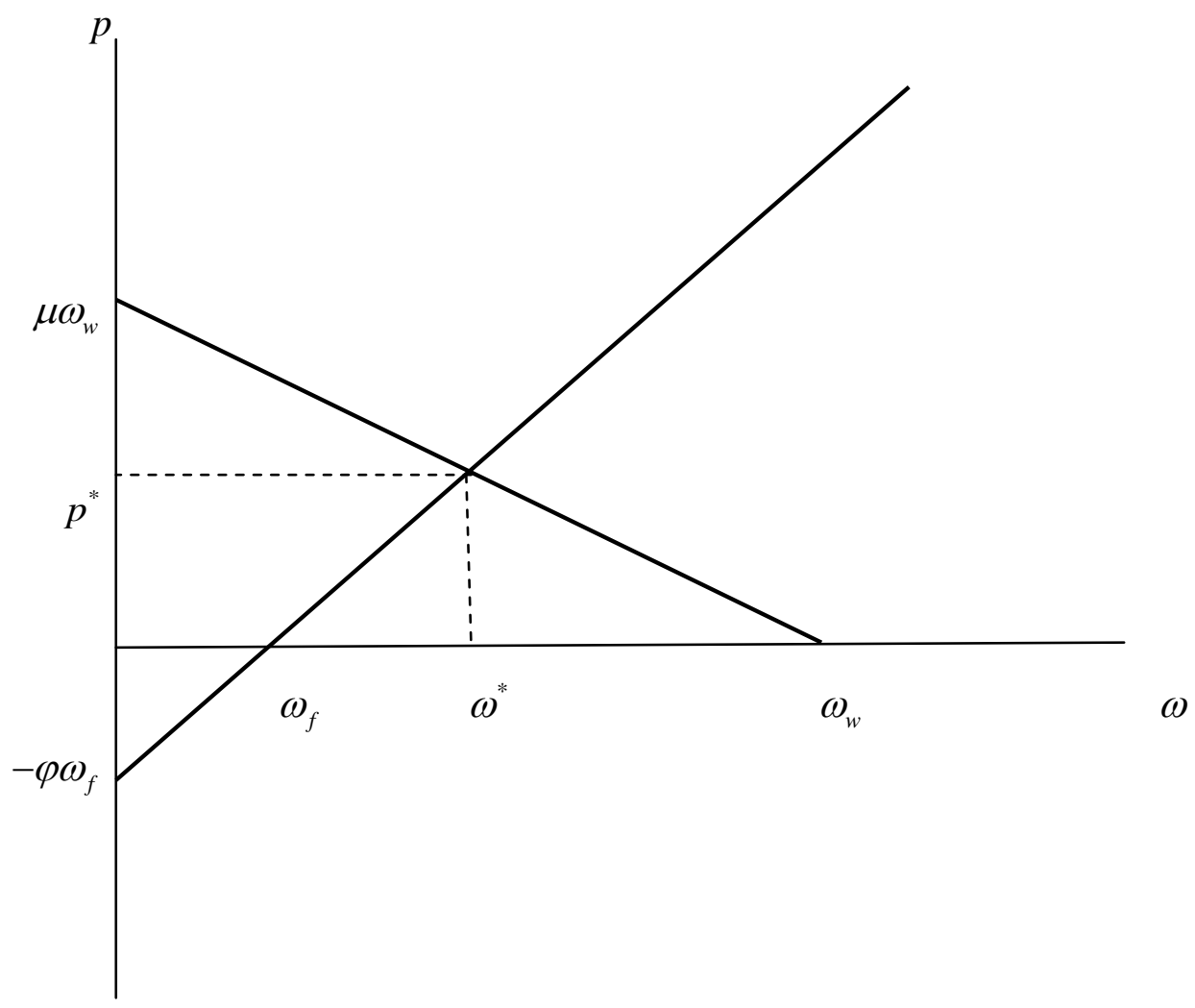


Figure 2: An equilibrium inflation regime

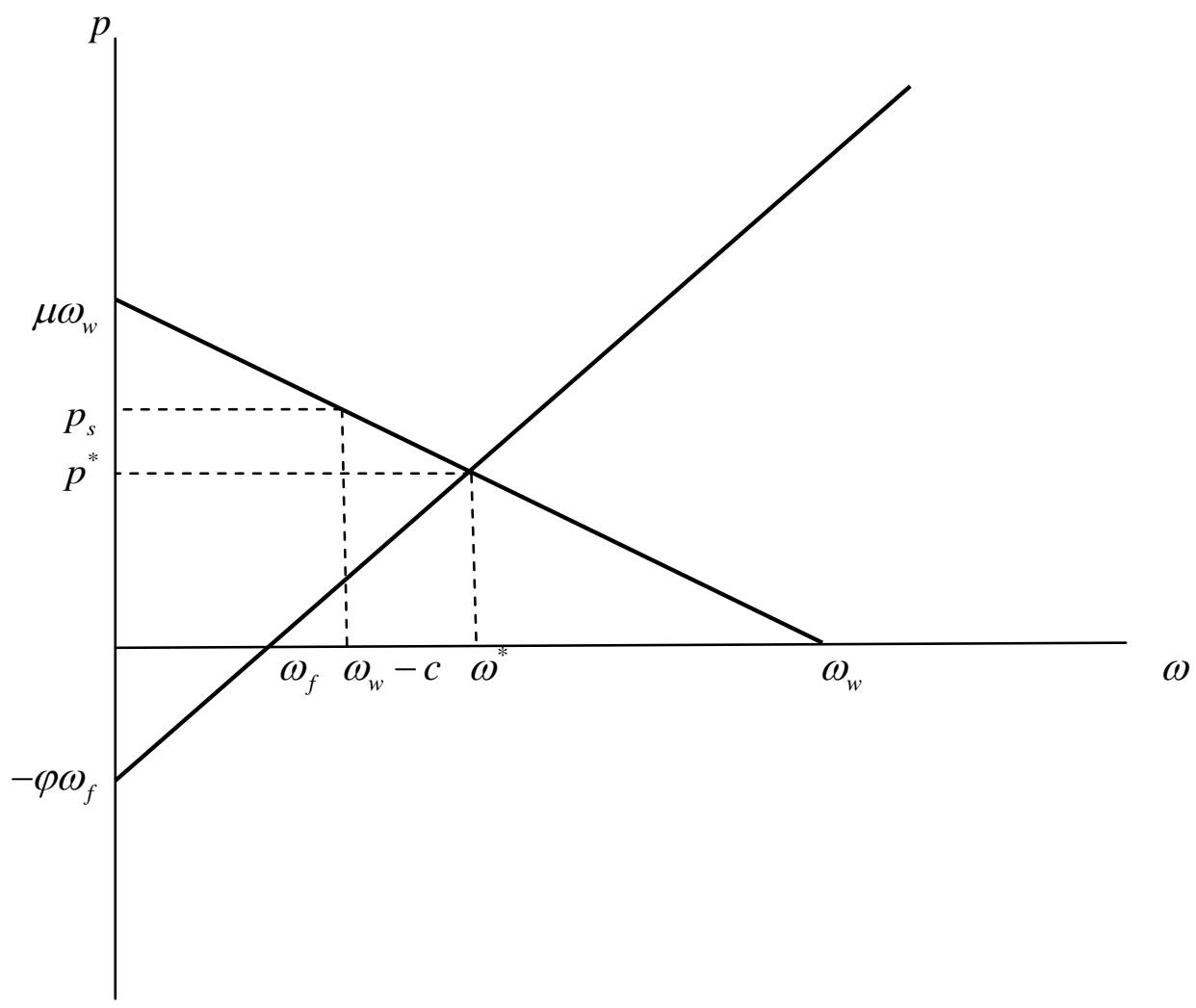


Figure 3: A strato-inflation regime

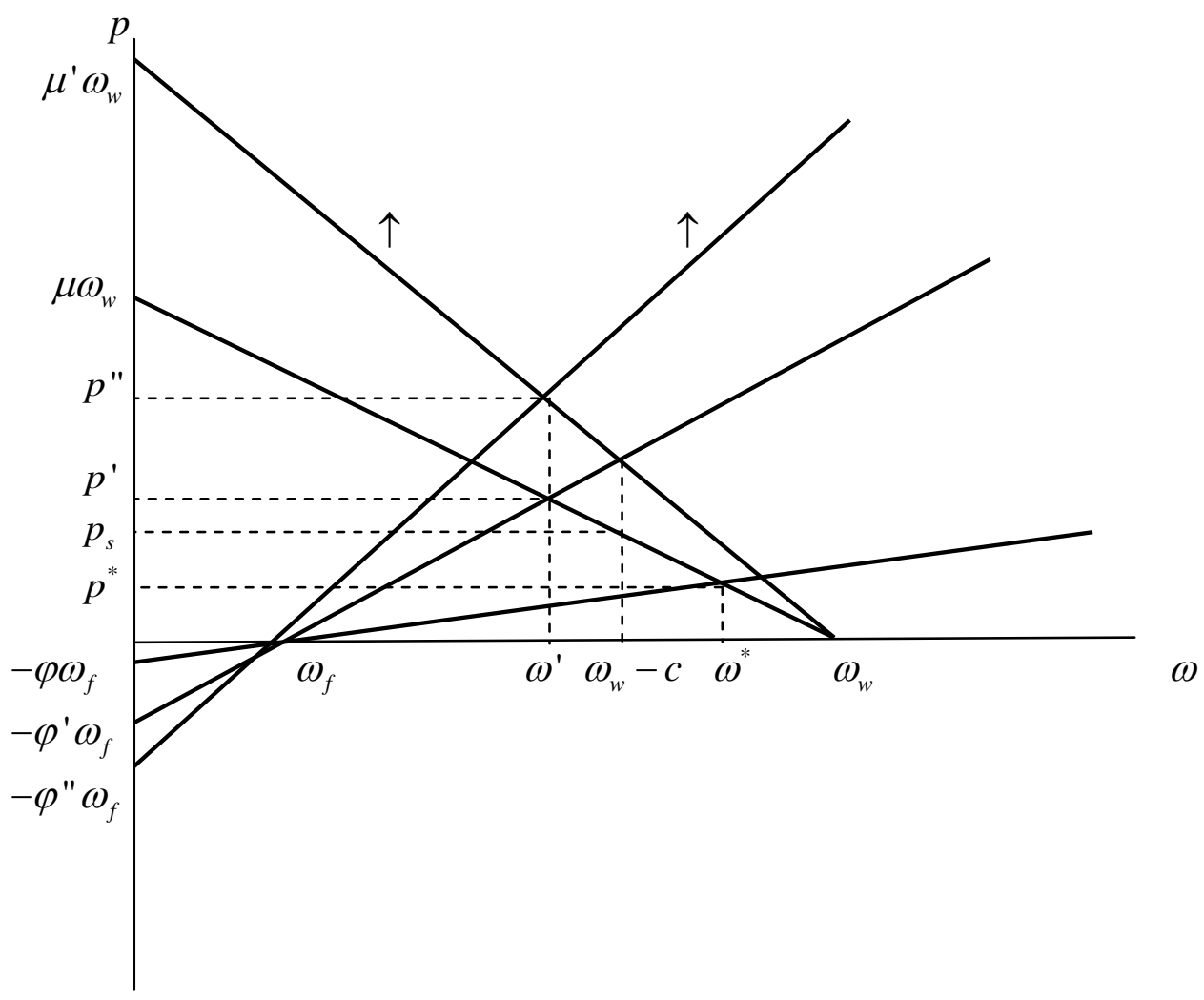


Figure 4: The marginal impact on growth of the initial transition to strato-inflation

a) Decomposing the growth rate effects

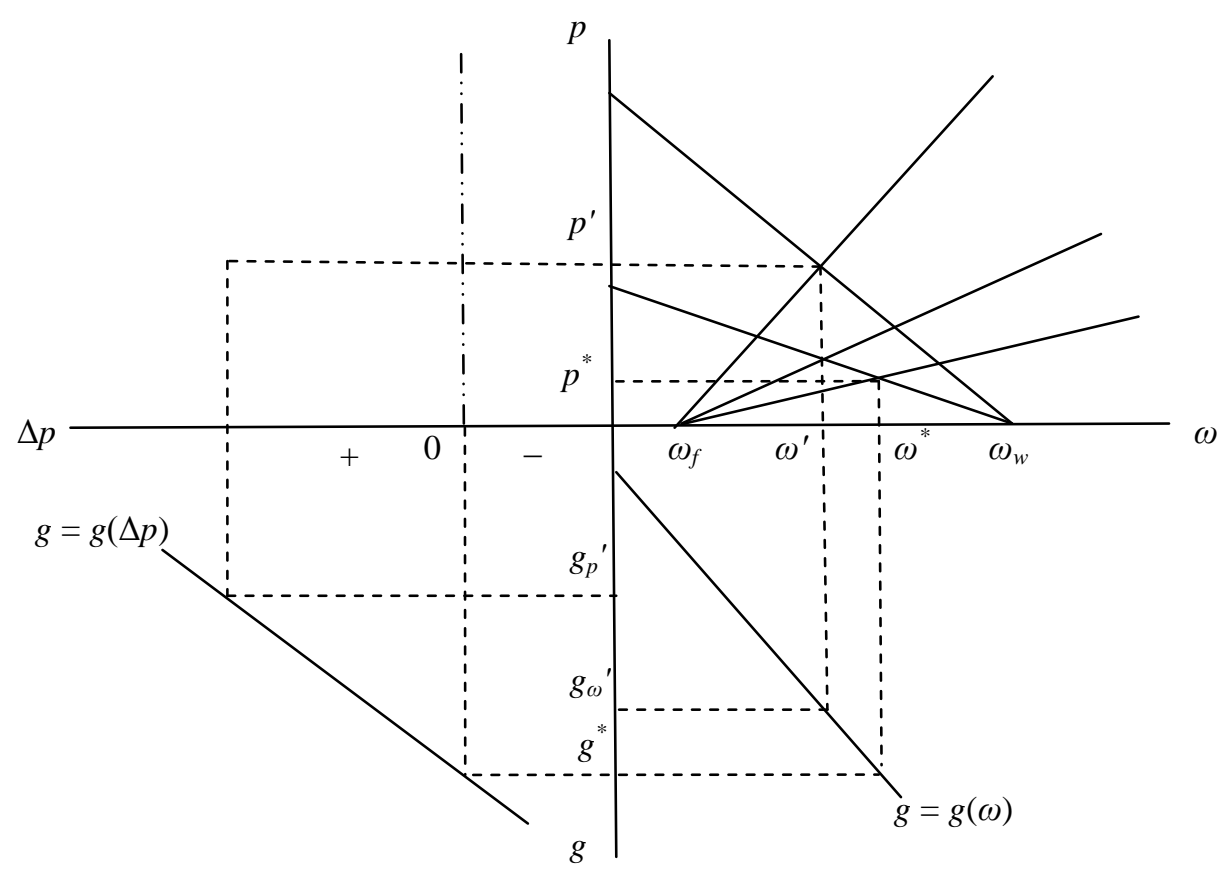

b) Evaluating the overall effect on equilibrium growth

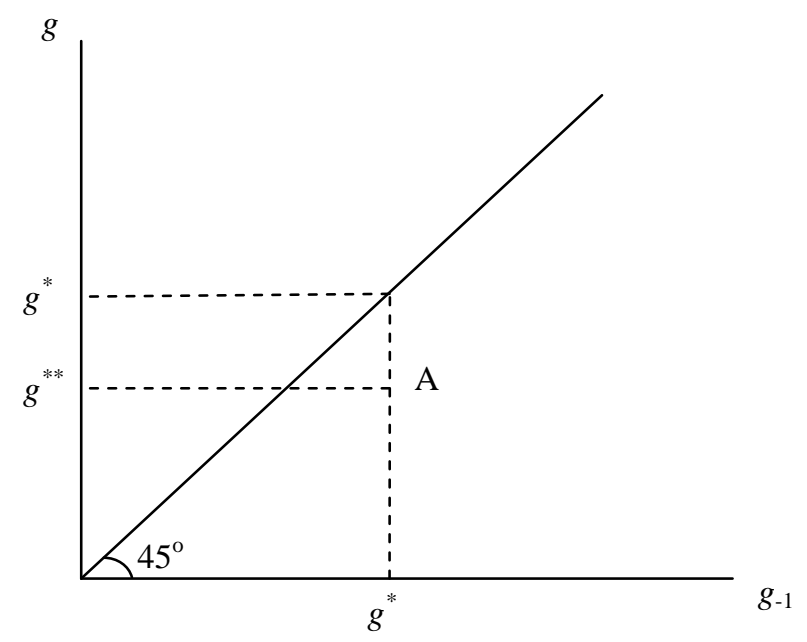


Table 1: The growth effects of continued strato-inflation

\begin{tabular}{|c|l|c|c|c|}
\hline \multicolumn{2}{|c|}{} & \multicolumn{3}{c|}{ Inflation } \\
\cline { 3 - 5 } \multicolumn{2}{|c|}{} & Accelerates & $\begin{array}{c}\text { Increases at } \\
\text { Constant Rate }\end{array}$ & Decelerates \\
\hline \multirow{4}{*}{ Wage Share } & Increases & $?$ & + & + \\
\cline { 2 - 5 } & Remains Constant & - & $\mathbf{0}$ & + \\
\cline { 2 - 6 } & Decreases & - & - & $?$ \\
\hline
\end{tabular}


Figure 5: The marginal impact on growth of the continuation of strato-inflation when inflation accelerates and the wage share increases

a) Decomposing the growth rate effects

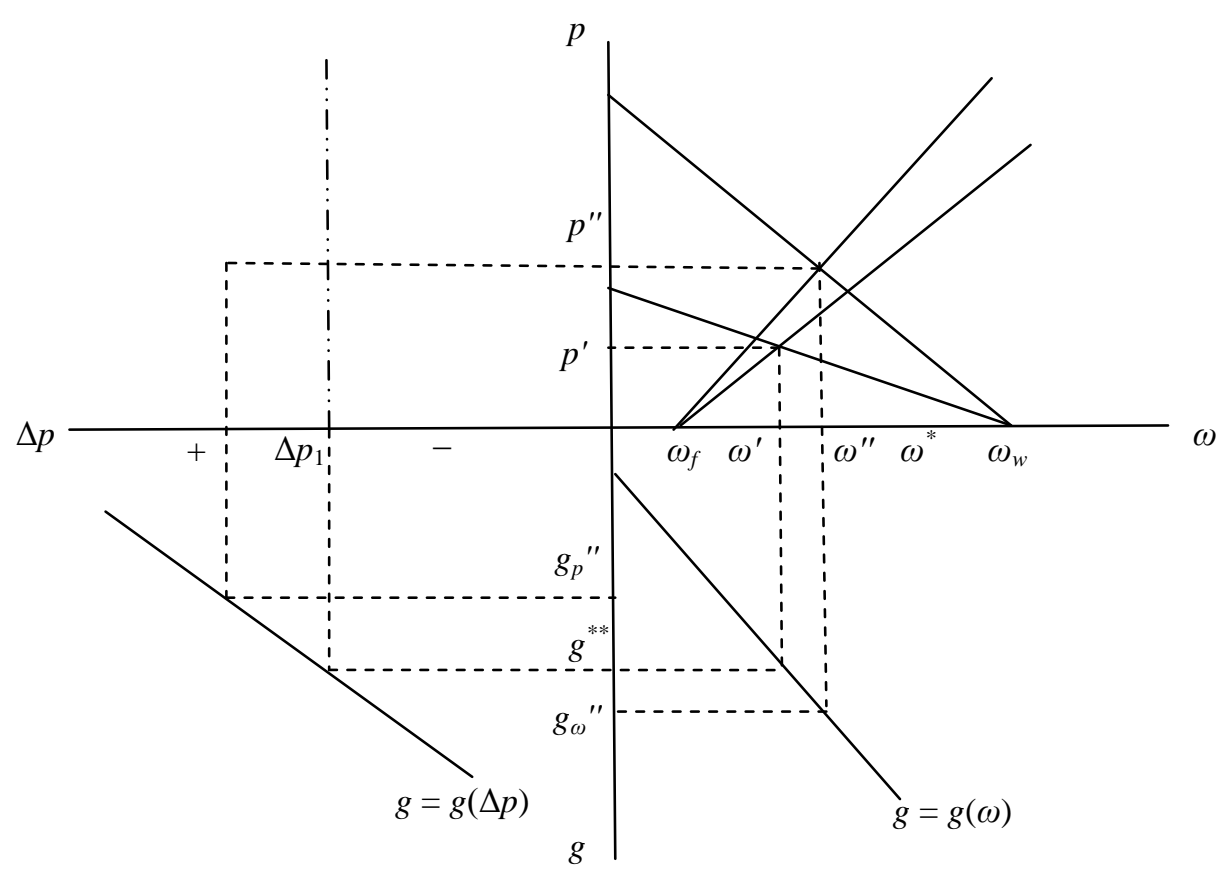

b) Evaluating the overall effect on equilibrium growth

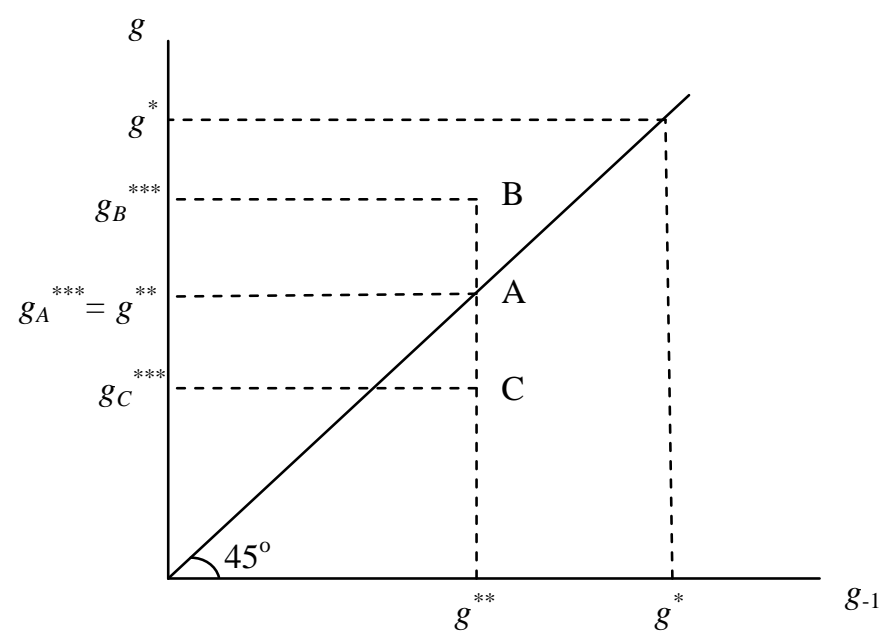

